\title{
Graffiti on bridges-aesthetical assessment
}

\begin{abstract}
The article looks into the problem of graffiti on bridges. Graffiti can be seen as a form of artistic expression. There are quoted two historical examples of graffiti, one of the times of antiquity and the other from a more recent historical period, i.e. 1840s. There has been an attempt to define graffiti on the basis of a survey conducted among the Lublin graffiti circles. The resulting descriptive definition of graffiti indicates a stable, independent or even illegal action which seems to be impossible to be curbed. The graffiti was examined on some examples of Santiago Calatrava's bridges. By means of a simple statistical method applied to the results of a survey conducted among student groups and by means of $1 / 0$ estimation (positive-1/negative-0 impression) of graffiti on bridges, some reliable results have been obtained. It was concluded that, optionally, some of bridge graffiti can be accepted and therefore can be kept as an enhancement of urban surroundings.
\end{abstract}

Volume 3 Issue 2 - 2017

\section{Slawomir Karas}

Department of civil engineering and architecture, Lublin

University of technology, Poland

Correspondence: Slawomir Karas, Lublin University of Technology, Lublin, Poland, Tel 0048 607I8I I I8,

Emails.karas@pollub.pl

Received: April 29, 2017 | Published: July 18, 2017

Keywords: bridges, aesthetics, graffiti

\section{Introduction}

Graffiti is, by definition, a form of writing, scribbling, scratching or distributing paint over a hard surface, on a public wall, illegally and anonymously. On the other hand, an entirely legal and considered a form of art is s graffito, architectural decoration of walls. The prototype here can be Paleolithic images, 40 to 10 thousand years B.C. found in the caves of Cro-Magnon, Lascaux, and Altamira. Today, it is difficult to decide if those works of art were in any way legal or not. Certainly, the painting technique was similar to today's graffiti. During the Hellenistic Period in Greece, inscriptions were carved in the stone of walls. A relevant example is presented in Figure 1. It is an inscription indicating a person whose name signified somebody powerful and extraordinary.

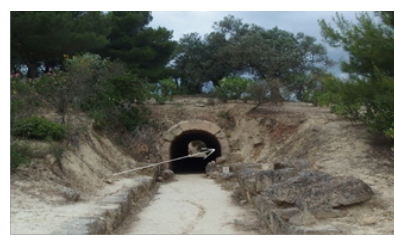

(A)

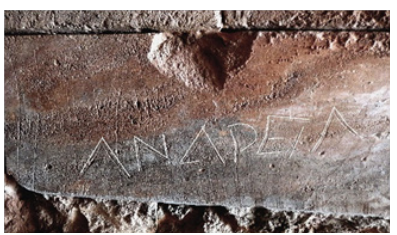

(B)
Figure I Nemea, Peloponnese: (A) stadium entry. (B) antique graffiti on a tunnel slab underlined by a white line.

Not always writing on walls was a form of artistic expression. Quite often, it was a form of political fight. In Poland, this type of communication emerged in 19th c. On buildings, or rather their walls to be precise, satirical texts against the Tzar were put. In was an illegal activity from the legal point of view, and the content of the texts vulgarised officials or institutions.

Inscriptions on walls often conveyed important information which in such a manner reached the interested parties. In Warsaw, there are inscriptions from the period after the city liberation in 1945 to be found informing that the area was clear of mines. These inscriptions are preserved and protected at present. Figure 2 shows such information located in Wawelska Street. A more civilised form of graffiti is urban murals, often adorning exposed top walls of terraced blocks of flats and tenement houses. The fact of being "civilised" excludes this form of wall painting from the graffiti movement.

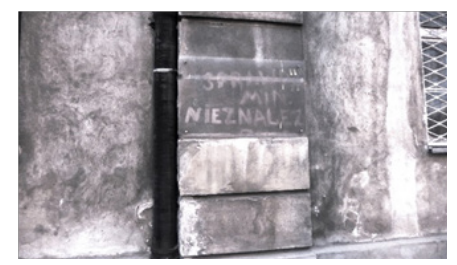

Figure 2 Graffiti-information, Warsaw, Ochota, Wawelska Street: checked mines not found.

\section{Who are graffiti artists and what is graffiti?}

Graffiti poses a challenge as almost nobody looks into the question of graffiti and people who choose this form of artistic expression. Let us try and identify and define graffiti and graffiti artists on the basis of the Polish graffiti milieu in the context of bridge graffiti. The proposed definition is relevant to the reflections in the article and as such may not be generally universal and subject to criticism. No doubt, graffiti is essentially an artistic activity inextricably linked to underground activities. Most often anonymous, illegal, persecuted and penalised (Figure 3). Real graffiti is a form of protest of the young generation. They are commonly unaccepted, to say the least. They cannot and do not want to adjust to hierarchical cultural and social circumstances. Nobody, or almost nobody outside of their circles, understands their art, their message, and, above all, their protest. It is the art of confused but defiant and energetic teenagers ready to fight their fight. ${ }^{1}$

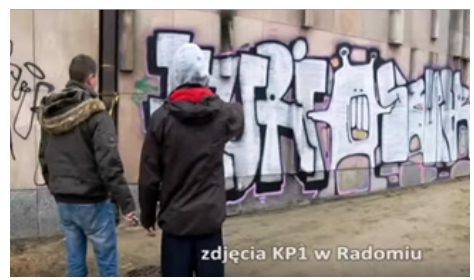

Figure 3 Police arresting a graffiti artist caught in the act on a bridge abutment wall. 
They use spray paints. In most cases they are uneducated in the area of fine art, com-position or painting techniques. They are amateurs. Very often, they have not received any form of education. The subject or issues addressed in their art are not defined. Here, the act of creation is the most important and in this sense it is a painting technique. The action of creating is not synonymous to the act of creating. A graffiti artist works alone or, paradoxically, as a member of an action group, very well prepared logistically. Under-ground is understood as secrecy, the activity is hidden from parents, teachers, out-of-school environment or any other.

Bridges are a perfect place for graffiti actions. Here, two options can be detected. In the first variant, the subjects of the actions are old, existing bridges usually neglected and for that reason attractive. A graffiti artist creates images referring to the existing state of deterioration or beautifying it. In the second option, a new and clean bridge tempts with the easiness of protesting against civilization conformism. A new bridge is an emanation of social prosperity or even success, and that is why it is a perfect instrument of signalling contrast to withdrawn individuals, marginalized by their maladjustment. The above description of the graffiti movement and artists is a conclusion of a several interviews conducted with graffiti artists from Lublin. It is not a strict definition, but functions as a basis for identifying a graffiti artist sending their own individual message with a strong tint of elitism and narcissism.

In the past certain parallels with graffiti as a phenomenon can be spotted, namely recurring protests against the forms of art officially regarded as correct and academically acceptable. They are commonly known as crises and turning points in the history of art, i.e. painting, architecture and music. One of the most popular events of this kind was the unofficial Salon de Refusés ${ }^{2}$ in Paris in 19thc. (1830). Salon de Paris was a yearly summary of French/Parisian artists' activities where respectable paintings, suitable for Parisian living rooms, were presented. Only works positively assessed by the Academy of Arts were accepted for the exhibition. Participating in the Salon was a gateway to a career in art. Nevertheless, the Salon became artistically ossified and did not keep up with new trends in art. A breakthrough came with two Eduard Manet's scandalising paintings, The Luncheon on the Grass (1862) presented at the Salon and Olympia (1863), shown at the Salon de Refusés. The monopoly of the Salon was broken and the rejected artists acquired a new path to the artistic establishment.

The history of crisis in art, referred above in short, cannot apply to graffiti. Any form of academism, conformism or commercialization excludes graffiti artists. From this moment on, they can be established artists but not graffiti artists any more. Of course, there exist albums and scientific papers on graffiti, but it is always an external evaluation, in the context of graffiti - an art critic's irrelevant, passive assessment, e.g. ${ }^{2-4}$ Graffiti, similarly to the Internet, is an open activity. Anybody of an adequate intellectual and technical potential can participate. For this reason, the contents of graffiti images vary to great extent. It is generally assumed that a political statement on a wall is accept-able, while bad language or expressions of anti-Semitism and racism are reprehensible in the Polish and European cultures. Unfortunately, these happen quite often and the reaction of relevant authorities responsible for a given bridge or building is not always prompt enough. Automatically, this essentially marginal sub-group of images is noticed quickly and strongly influences how graffiti is perceived.
Considering graffiti and its artists, one should clearly distinguish between the art of graffiti ${ }^{5}$ and the activities of random people around a bridge. Usually, such people are the authors of extremely vulgar inscriptions and drawings, directly corresponding to their intellectual capacity - more often than not. In terms of art, this is not graffiti. No matter how favourable an attitude towards graffiti, there is always the counter-point of vandalism. From the point of view of an appropriate, classical image of bridges, the art of graffiti is a form of vandalism which has a distinct financial dimension, e.g. when choosing sprayresistant paint or cleaning an object from existing permanent and colourful images. ${ }^{6}$ This dramatic choice boils down to two options: getting used to it-or fighting it. Knowing the nature of the art of graffiti, and especially its rebellious spirit, each of the options equally lack effectiveness, which does not mean at the same time, that they are completely useless.

\section{Graffiti on bridges}

\section{Aesthetic discussion of graffiti images}

There is no accounting for taste, but the expressions of either approval or disapproval can be statistically measured. The above images have been assessed by groups of Polish and Erasmus students at Road and Bridge Department at Lublin University of Technology. The number of students in subsequent tests was from 12 to 20 , see (Figure 4). The selected assessing group is not statistically unbiased. They are $2^{\text {nd }}$ year students majoring in roads and bridges, who, as a result of their education, perceive graffiti on bridges as vandalism. Precisely for this reason, positive assessment cases are so interesting. The following assessment method was used: 1 - positive impression, 0 - negative impression.

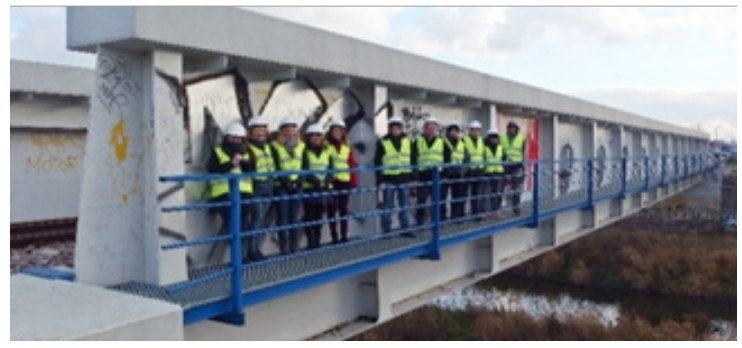

Figure $4 \mathrm{~A}$ group of students conducting an assessment of the aesthetics of graffiti on bridges.

\section{Selected monumental santiago calatrava's bridges}

The subject of graffiti on bridges is tightly connected with a presentation of images. At the same time, these images should be regarded from the point of view where one image is worth a thousand of words and by "images" one should understand the enclosed photographs. The whiteness of bridges and their elegance pose significant challenge to graffiti artists. Maybe this is the reason why they are not particularly active with regard to Calatrava's bridges. It does not mean, however, that writing on them does not take place. Monumental Calatrava's works defend themselves through their very size. Spraying pylons and arches would require extraordinary climbing skills. For this reason, the exiting graffiti images to be found are relatively small and uninteresting compared to the total structures of the bridges, which does not mean at the same time, that they leave a viewer unimpressed in any way Santiago Calatrava is nowadays 
the most recognizable bridge constructor - via his works. Calatrava has designed monumental white bridges. The colour white is strong and pure. It may be simply his personal preference, but also a natural transposition of the white of the Mediterranean architecture, especially the Spanish one. Now, one can talk about his followers - the designers whose bridges refer to Calatrava's in terms of structure. Although the structural innovativeness of Calatrava's bridges is difficult to match, the colour white is used frequently. An example here can be the commonly known footbridge Ponte della Musica in Rome, ${ }^{7}$ or the foot and bicycle bridge in Szczebrzeszyn, ${ }^{8}$ which is so new that it has not been covered in graffiti yet. It is worth mentioning this is the first white bridge in Poland, certainly follows Calatrava examples.

The bridge, unofficially called Puente Blanco (Figure 5), was constructed in 1991. The inscriptions sprayed on the concrete arch portals are, from the aesthetical point of view, rather common and uninteresting. The same can be said about the graffiti on the abutments, although in this case it is a full blown graffiti.

What is more, the underside of the superstructure is a rhythmic system of partition gilts of ellipsoidal edges similar to the stiffener in R. Maillart's ${ }^{2}$ bridge in Garstatt of 1939. Two other Calatrava's bridges, in Athens and Venice respectively, have been subject to graffiti artists' minor interventions. The Katehaki footbridge is considered the most beautiful of Calatrava's bridges. ${ }^{9}$ It has an element of yearning for more. Its lightness and charm of a Mediterranean sailing ship seduce the viewer, but it is fitted so thoroughly into the mediocre environment of the Katehaki residential area that it is not visible in its entirety. Maybe this element of yearning for more was an intentional architectural measure (Figure 5A). Actually, the only area accessible to graffiti is the bridge supports. There are some insignificant inscriptions on one of them which can only be qualified as graffiti by a very friendly viewer. They are rather accidental scribbles. It can only be noted that their role in how the bridge is viewed is comparable to the designed greenery visible in (Figure 5B).

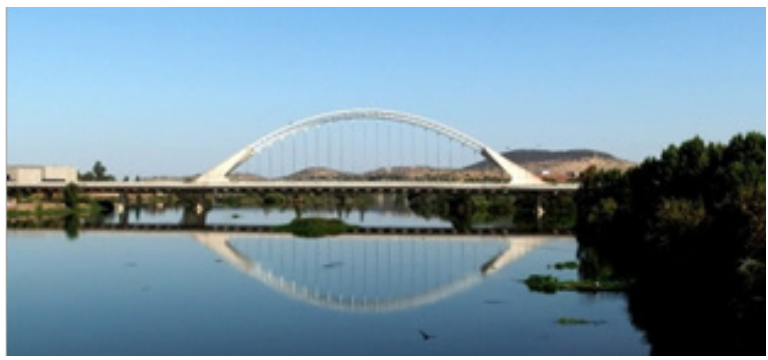

$5(A)$

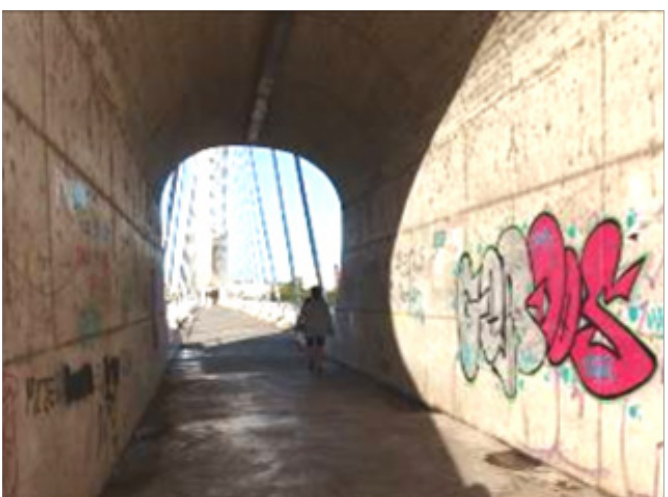

$5(B)$
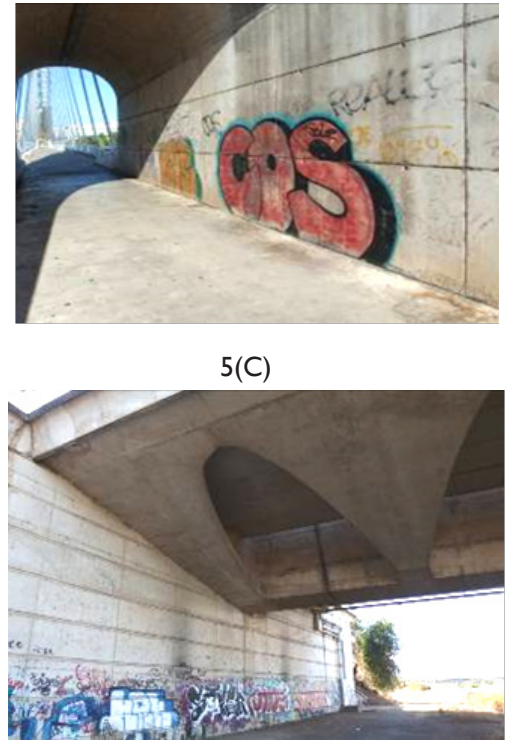

$5(\mathrm{D})$

Figure 5 Lusitania Bridge (Puente Blanco), Mérida, Spain:A) side view B) - C) graffiti on the portal gates of the arch $\mathrm{D}$ ) on an abutment.

The bridge was constructed simultaneously with highly impressionistic Olympic stadiums in 2004. Calatrava, when visiting Athens, admitted that he had designed it as homage to the ancient architecture and, generally, the Greek civilisation. (Figure 6) shows beautiful but controversial Ponte della Costituzione (Ponte di Calatrava) in Venice, assembled in 2007. Constructing a monumental bridge in Venice is a highly difficult task, a challenge. Calatrava combined the colours of Venice with limited - and appropriate with regard to the city - dimensions. The bridge is located in the perimeter of the old town and refers to three other historical bridges over Canal Grande. At the same time, it is different as its arch is decisively gentle and modern. The courageousness of its shapes makes it soft.

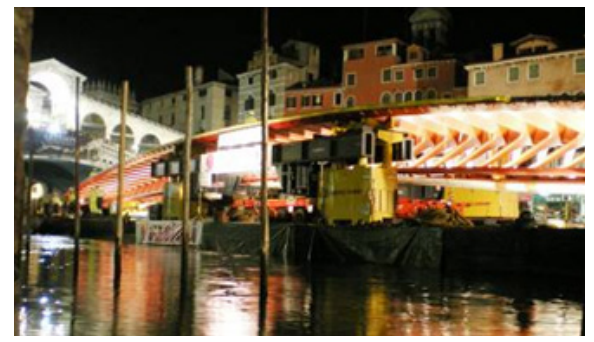

$6(\mathrm{~A})$

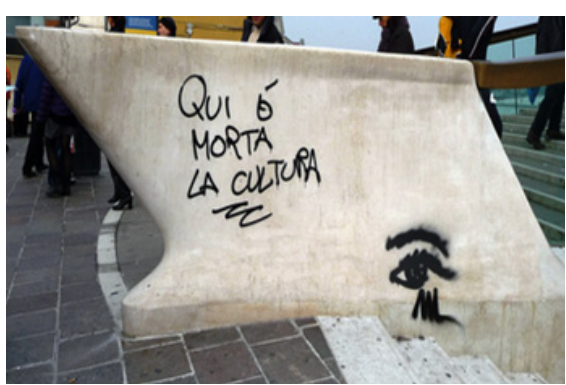

6(B)

Figure 6 Ponte di Calatrava footpath in Venice, 2007: A) bridge structure transport over Canal Grande B) an artistic manifesto. 
Its exquisite framework resembles a fish skeleton. The basic partition gilt is located on the bridge axis. The gilt is supported by leaning frameworks which resemble trusses without cross-braces. The supports of footpaths protrude from the partition gilt forming a horizontal frame. In the cross-section, the absolute transparency of the red steel structure combined with a transparent glass platform can bring to one's mind an image of a butterfly (it. farfalla). The bridge meets all the requirements regarding the traffic gauge necessary for the movement of Venetian water buses (vaporetto). Will the bridge be accepted? Hard to say at the moment. (Figure 7) shows a protest, an artistic manifesto expressing the utmost doubt about Calatrava's work. Moreover, the bridge has not been made available to the public entirely. Its glass landing and a plateau in the entrance have caused accidents, limb dislocations, which required medical interventions. Temporarily, at the entrances to the bridge signposts forbidding entry for people with locomotive disabilities have been put. Any inscriptions put on the bridge are immediately removed.

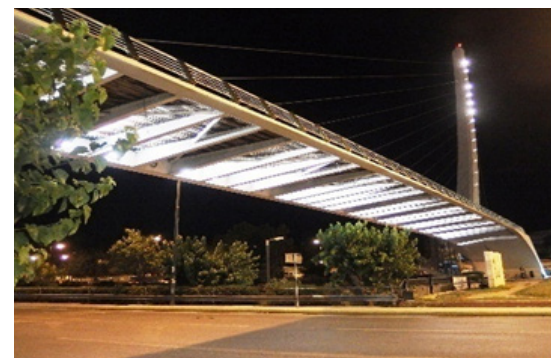

$7(\mathrm{~A})$

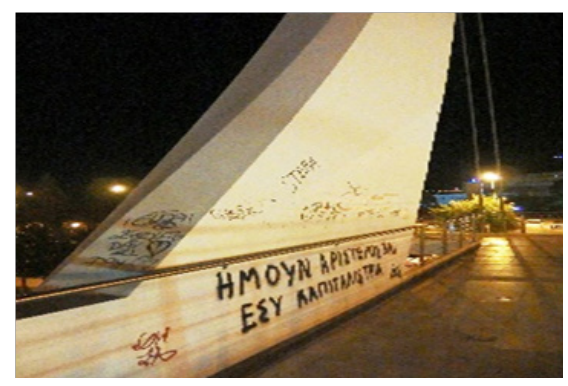

$7(B)$

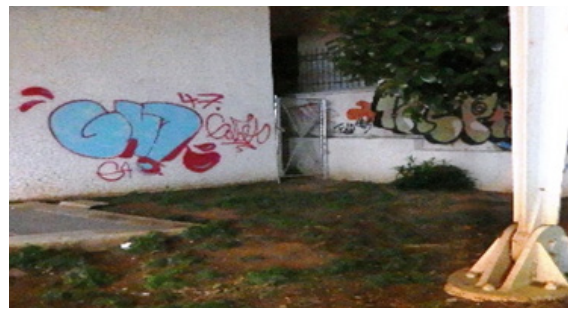

$7(\mathrm{C})$

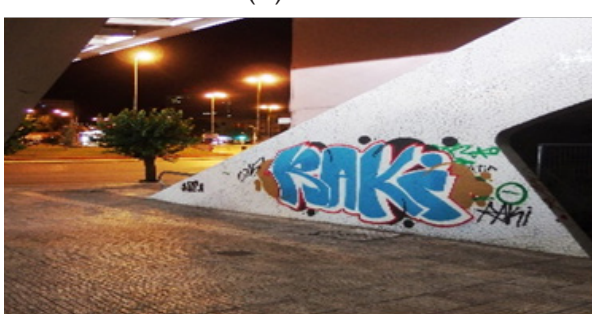

7(D)

Figure 7 Katehaki Footbridge, Athens, 2004:A) view on the bridge B) none C) none $D$ ) ungentle graffiti.
Calatrava's Venetian bridge illustrates well that even in the case of an architectural excellence, one should take into consideration approach differences when in historical urban areas.

\section{Information boards}

This section is dedicated to information boards principally for the reason of their non-existence in Poland. It is these short and skil fully written outlines that help identify the bridge in question. Figure 8 presents a few examples that seem to be a good reference material. They usually combine some illustrations of the past with the designer's and developer's data. In the environmental context, there is some information about flora and fauna of the area surrounding the bridge. Information boards are also useful for graffiti purposes while it is not the case of artistically captivating graffiti. Most often, there are some disconnected reflections characterizing their author, quite often one encounters intimate expressions of deep feelings. There are no doubt those inscriptions visible in (Figure 6) are not the graffiti art and bear all the marks of vandalism.

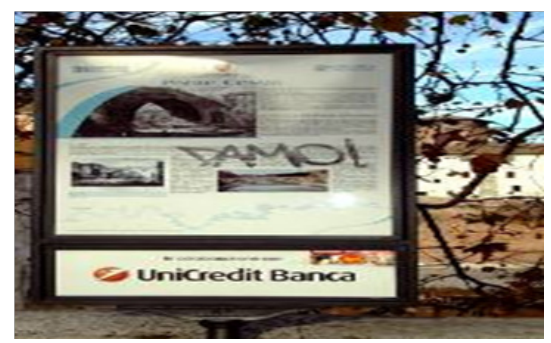

$8(A)$

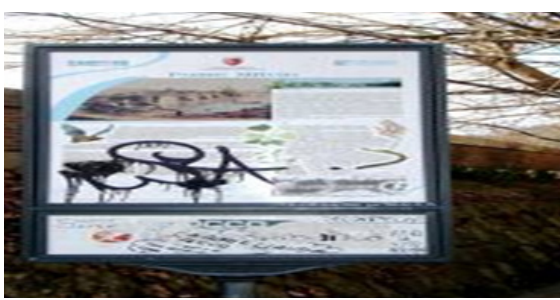

$8(B)$

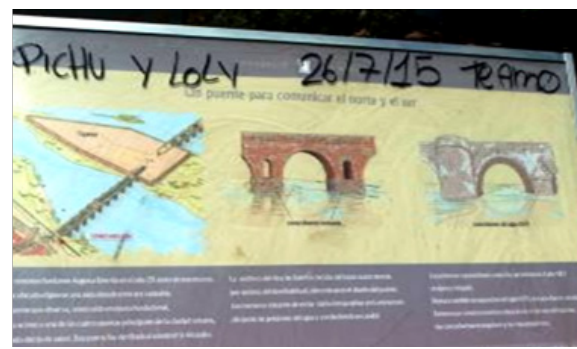

$8(C)$

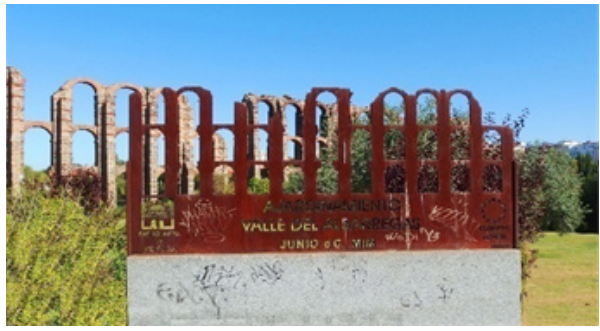

8(D)

Figure 8 Information boards near bridges:A) - B) Rome C) - D) Mérida, Spain. 


\section{Average bridges}

Contemporary image manipulation procedures enable a comparison of situations where graffiti is present or not. Let us analyse the subway in a railway embankment in this context, (Figure 9). The results of all the five tests were positive with the proportion of approx. $6 / 4$ of the participants' number. In the discussion which followed the most frequent argument in favour was how graffiti enlivened the plain wall. The attention was drawn to the dark colour of the wall which is seldom used in Poland but common in Spain. The negative voices stemmed from a discontent about the heterogeneous form of the graffiti, which, apart from elaborate images, contained commercial or election posters and random inscriptions, as well. Two structures in Lublin and Badajoz (Figure 10) have been similarly assessed, although directly, without a manipulated image for comparison (Figure 9). In both cases the results were positive at a decisive number of participants. In the case of the pedestrian subway the emotional assessment was rather low, while with regard to the Lublin bridge a discussion about the bad technical condition of the bridge resulting from inappropriate maintenance ensued. In such circumstances, the graffiti on both abutments was perceived as a moderating factor of the depressing image of the reinforced concrete corrosion. The three images in (Figure 11A-11C) have been assessed negatively.

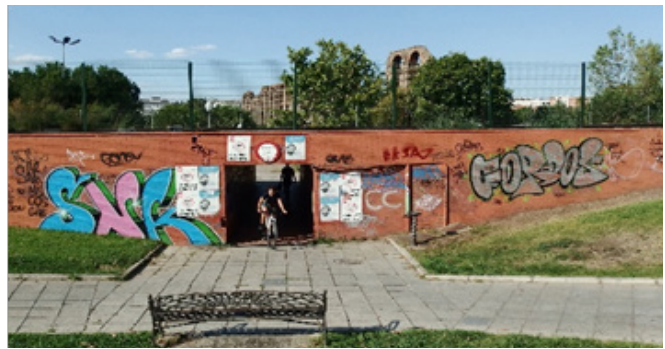

$9(\mathrm{~A})$

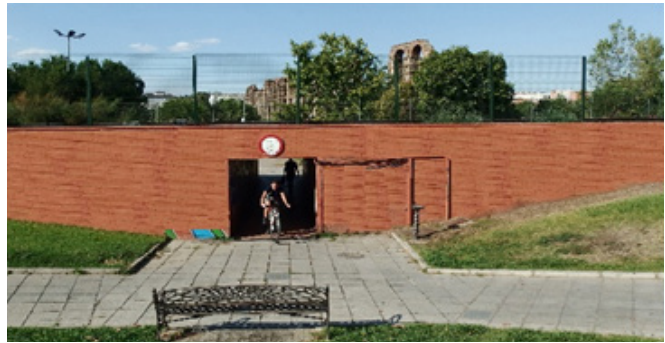

9(B)

Figure 9 Pedestrian subway in a railway embankment, Mérida, Spain:A) factual status B) the embankment with the graffiti removed.

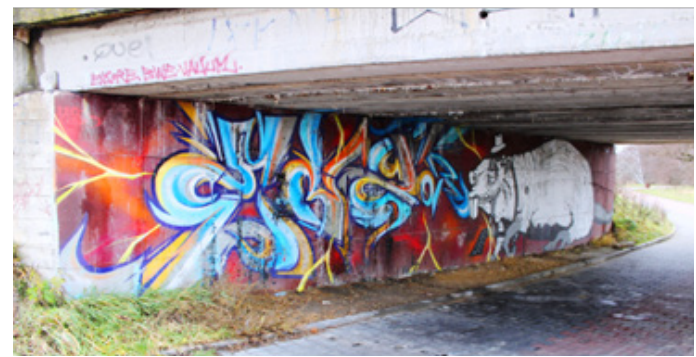

$10(\mathrm{~A})$

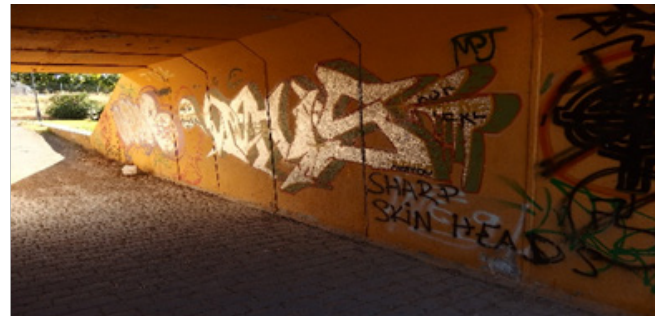

I0(B)

Figure 10 Interesting graffiti:A) The abutment wall of the bridge in Lublin B) pedestrian subway in Badajoz.

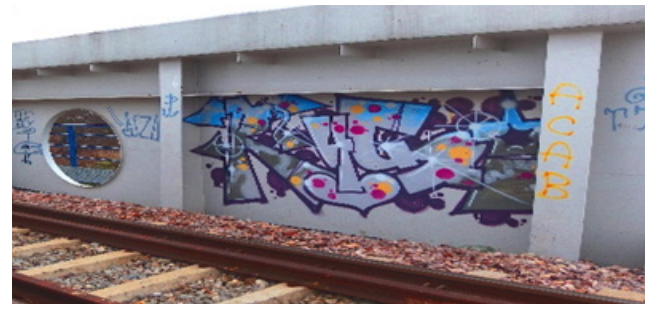

II (A)

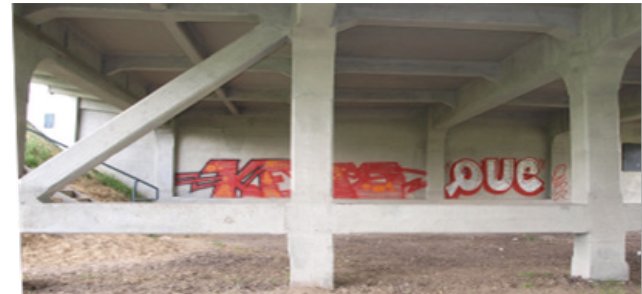

I I(B)

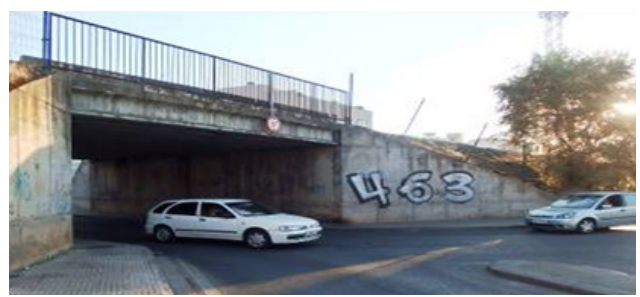

II(C)

Figure II Negative assessment of graffiti: A) a Vierendeel bridge B) M. Lutosławski bridge C) prefabricated rail viaduct.

The three images in (Figure 10) have been assessed negatively Figure 11A shows a new Vierendeel bridge, located in Turystyczna street in Lublin. In (Figure 11B) one can see the renovated Marian Lutosławski Bridge of 1909, over the Bystrzyca river along Zamojska street. ${ }^{10}$ In both cases the assessment was negative and resulted from a strong identification with the Lublin bridges. Conducting classes in bridge-related subjects at the faculty of is, by definition, connected with interesting bridges of the region. Probably for this reason the assessment was negative, despite the fact that the graffiti itself was perceived as interesting. The third image in (Figure 11C) presents an ugly (whatever it means) bridge with equally nondescript graffiti. The suggested harmony of both aesthetically equal elements moderated the uncompromisingly negative perception, but did not change it. The results of the evaluation are summarized in (Table 1). 
Table I Detailed and final graffiti aesthetics assessments on bridges

\begin{tabular}{lllllll}
\hline No & Object & I - Positive quantity & [\%] & $\mathbf{0}$ - Negative quantity & [\%] & Result \\
\hline Figure 5 & Lusitania Bridge & 2 & 17 & 10 & 83 & Negative \\
Figure 6 & Katehaki Footbridge & 0 & 0 & 15 & 100 & Negative \\
Figure 7 & Ponte di Calatrava & 2 & 13 & 13 & 87 & Negative \\
Figure 8 & Information boards & 0 & 0 & 17 & 100 & Negative \\
Figure 9 & Subway, Mérida & 11 & 58 & 8 & 42 & Positive \\
Figure I0a & Abutment wall, Lublin & 12 & 63 & 7 & 37 & Positive \\
Figure I0b & Subway, Badajoz & 15 & 75 & 5 & 25 & Positive \\
Figure I la & Vierendeel Bridge & 3 & 15 & 17 & 85 & Negative \\
Figure IIb & Lutosławski Bridge & 1 & 8 & 11 & 92 & Negative \\
Figure IIc & Abutment wings, Mérida & 8 & 42 & 11 & 58 & Negative \\
\hline
\end{tabular}

Considering the fact that, so far, a methodical verification of graffiti has not been undertaken in Poland, it seems that the a fore described method could be applied when deciding the fate of existing graffiti images on bridges, more or less arbitrarily. Another argument in favour of this solution is the painful alternative of the illusory procedures aimed at limiting graffiti.

\section{Conclusion}

The above considerations are a result of the author' extracurricular interests, apart from bridge structure mechanics. A descriptive outline definition of graffiti has been put forward the basis of an inquiry into the artistic concepts of the Lublin graffiti milieu. By means of a simple statistical measure some bridges with graffiti have been assessed, while a few chosen were discussed in the article. The applied definition seems to be relevant with regard to the issues discussed in the article, although cannot be perceived as universal and as such it is subject to discussion.

The conclusion can be formulated by analogy to the problem of forest clearance - it is not the clearance which poses the problem, but planting new trees. Things could be the same in the case of graffiti. It is a defined process which, as it seems, cannot be stopped. Therefore, pseudo-graffiti images, especially those highly vulgar, racist, anti-Semitic, xenophobic or stemming from other socio-political worldviews generally regarded as harmful, should be removed, while others, rationally assessed, could be kept. A premise for such a moderate view on graffiti is the undeniable beauty of many of the images created on bridges. Voices stemmed from a discontent about the heterogeneous form of the graffiti, which, apart from elaborate images, contained commercial or election posters and random inscriptions, as well.

Two structures in Lublin and Badajoz (Figure 10) have been similarly assessed, although directly, without a manipulated image for comparison (Figure 9). In both cases the results were positive at a decisive number of participants. In the case of the pedestrian subway the emotional assessment was rather low, while with regard to the Lublin bridge a discussion about the bad technical condition of the bridge resulting from inappropriate maintenance ensued. In such circumstances, the graffiti on both abutments was perceived as a moderating factor of the depressing image of the reinforced concrete corrosion. The three images in (Figure 11A-11C) have been assessed negatively.

\section{Acknowledgments}

None.

\section{Conflicts of interest}

The authors declare that there are no conflicts of interest.

\section{Funding}

None.

\section{References}

1. Ferrell J. Hiding in the light graffiti and the visual. Criminal Justice Matters. 2009;78(1):23-25.

2. Eck R, Martinelli G. Assessment and mitigation measures for graffiti on highway structures. Journal of the Transportation Research Board. 2014;1642:35-42.

3. Hughes ML. Street Art \& graffiti art developing an understanding. Thesis Georgia State University USA, pp. 2009:60.

4. Baird JA, Taylor C. Ancient graffiti in context. Taylor \& Francis eBooks pp. 2010:24.

5. Vanderveen G, Gwen van Eijk. Criminal but beautiful: a study on graffiti and the role of value judgments and context in perceiving disorder. European Journal on Criminal Policy and Research. 2016;22(1):107-125.

6. Rossi S, Fedel M, Petrolli S, et al. Behaviour of different removers on permanent anti-graffiti organic coatings. Journal of Building Engineering. 2016;5:104-113.

7. De candia M. Roma inaugura il ponte della musica firmato buro happold. Archi Portale pp. 2011:5.

8. Karaś S, Oskręda B, Skulski B, et.al. New Arch Footbridge in Szczebrzeszyn. Bridges pp. 2015:22-26.

9. Karas S. History of sustainable bridge solutions. Structural Bridge Engineering InTech pp. 2016:1-24.

10. Karas S. Unique hennebique bridges in Lublin. American Journal of Civil Engineering and Architecture pp. 2013:47-51. 